\title{
Tryptophan-Dependent Production of Indole-3-Acetic Acid (IAA) Affects Level of Plant Growth Promotion by Bacillus amyloliquefaciens FZB42
}

\author{
EISorra E. Idris, ${ }^{1}$ Domingo J. Iglesias, ${ }^{2}$ Manuel Talon, ${ }^{2}$ and Rainer Borriss ${ }^{1}$ \\ ${ }^{1}$ Humboldt Universität Berlin, Institut für Biologie, Berlin, Germany; ${ }^{2}$ Instituto Valenciano de Investigaciones Agrarias (I.V.I.A) \\ Centro de Genómica, Valencia, Spain
}

Submitted 12 October 2006. Accepted 3 January 2007.

\begin{abstract}
Phytohormone-like acting compounds previously have been suggested to be involved in the phytostimulatory action exerted by the plant-beneficial rhizobacterium Bacillus amyloliquefaciens FZB42. Analyses by high-performance liquid chromatography and gas chromatography-mass spectrometry performed with culture filtrates of FZB42 demonstrated the presence of indole-3-acetic acid (IAA), corroborating it as one of the pivotal plant-growth-promoting substances produced by this bacterium. In the presence of $5 \mathrm{mM}$ tryptophan, a fivefold increase in IAA secretion was registered. In addition, in the trp auxotrophic strains E101 $(\triangle t r p B A)$ and $\mathbf{E 1 0 2}(\triangle t r p E D)$, and in two other strains bearing knockout mutations in genes probably involved in IAA metabolism, E103 ( $\triangle y s n E$, putative IAA transacetylase) and E105 ( $\Delta y h c X$, putative nitrilase), the concentration of IAA in the culture filtrates was diminished. Three of these mutant strains were less efficient in promoting plant growth, indicating that the Trp-dependent synthesis of auxins and plant growth promotion are functionally related in B. amyloliquefaciens.
\end{abstract}

Enhancement of plant growth by root-colonizing Bacillus and Paenibacillus strains is well documented (Kloepper et al. 2004; Timmusk and Wagner 1999; Yao et al 2006). Moreover, plant-growth-promoting rhizobacteria (PGPR) of the Bacillus group offer a biological solution to the formulation problem due to their ability to form heat- and desiccation-resistant spores (Emmert and Handelsman 1999). However, very little is known about the basic molecular mechanisms responsible for beneficial action of the bacilli group of PGPR, preventing development of optimal application strategies for available formulations in agriculture and horticulture. It is very likely that plant growth promotion by rhizosphere bacilli results from the combined action of several factors. The volatiles 3-hydroxy-2butanone (acetoine) and 2,3-butanediol, released by Bacillus subtilis and B. amyloliquefaciens, trigger enhanced plant growth (Ryu et al. 2003). In previous studies, we showed that biofertilization exerted by extracellular bacterial phytase under conditions of phosphate limitation and in the presence of phytate can contribute to the plant-growth-promoting activity of $B$. amyloliquefaciens FZB strains (Idriss et al. 2002; Makarewicz et al. 2006). Suppression of the competitive plant-pathogenic microflora within the rhizosphere by secreted antifungal and antibacterial lipopeptides and polyketides might be important for promotion of plant growth by FZB42 (Chen et al. 2006; Koumoutsi et al. 2004). In addition, B. amyloliquefaciens FZB24 enhanced development of plant resistance against competitive pathogenic fungi and bacteria (Kilian et al. 2000).

It also is likely that plant-growth-promoting effects exerted by some plant-beneficial bacteria are due to the bacterial production of plant hormones such as indole-3-acetic acid (IAA), cytokinins, and gibberellins (Bloemberg and Lugtenberg 2001; Bottini et al. 2004). IAA was detected in $80 \%$ of bacteria isolated from the rhizosphere (Loper and Schroth 1986); however, reports demonstrating production of IAA by gram-positive free-living soil bacteria are still lacking. Synthesis of IAA by the gram-positive phytopathogen Rhodococcus fascians recently was reported (Vandeputte et al. 2005). Gas chromatographymass spectrometry (GC-MS) analysis verified gibberellin production by B. pumilus and B. licheniformis (Gutierrez-Mareño et al. 2001). We previously have shown that representatives of the B. subtilis/amyloliquefaciens group are able to produce substances with auxin (IAA)-like bioactivity. The presence of IAA-like compounds in the culture filtrates of several members of this group, including FZB42, was detected by enzymelinked immunosorbent assay tests with IAA-specific antibodies, when those strains were grown at low temperature and low aeration (Idriss et al. 2004).

Using a combined approach of chemical and genetic analysis, we demonstrate here that biosynthesis of IAA in the PGPR B. amyloliquefaciens FZB42 affects its ability to promote plant growth. Moreover, this ability is dependent on the presence of tryptophan, which is one of the main compounds present in several plant exudates (Kamilova et al. 2006). Inactivation of genes involved in tryptophan biosynthesis and in a putative tryptophan-dependent IAA biosynthesis pathway lead to reduction of both IAA concentration and plant-growth-promoting activity in the respective mutant strains.

\section{RESULTS}

Plant-growth-promoting activity

of FZB42 was demonstrated

in a Lemna minor-based, microtiter-plate assay.

Diluted culture filtrates or growing cells of FZB42 were able to stimulate plant growth in a test system developed from the duck weed clone, Lemna minor ST, grown in 48-well microtiter plates (discussed below). However, this effect depends on the concentration of the added bacterial supernatant or cells. Di- 
luted FZB42 culture filtrate at $0.1 \%$ caused a significant $(P \leq$ 0.01) increase in fresh weight compared with the control plants. Addition of higher concentrations of bacterial culture filtrate inhibited plant growth (Table 1). The stimulating effect on plant growth was even higher when growing bacterial cells in appropriate concentration $\left(2 \times 10^{5} \mathrm{CFU}\right.$ for maximal promotion) were added. Addition of higher numbers of bacteria $(>1 \times$ $\left.10^{7} \mathrm{CFU}\right)$ resulted in significant $(P \leq 0.01)$ reduction of plant fresh weight. This assay was used throughout this study in order to analyze plant-growth-promoting activity of FZB42 and the mutant strains described in the later sections.

\section{Identification and quantification of IAA by GC-MS.}

Phytohormone-like action of culture filtrates obtained from B. amyloliquefaciens cells grown at $22^{\circ} \mathrm{C}$ and low aeration was demonstrated previously (Idris et al. 2004). In order to identify the chemical compound responsible for the plant-growth-promoting activity, culture filtrates of FZB42 were separated by analytic high-performance liquid chromatography (HPLC) and further analyzed by mass spectrometry, as described below. Full-scan GC-MS analyses of authentic IAA showed that the fragmentation pattern of this compound produced two main ions, m/z 202 and 261 (Gaskin and MacMillan 1991) at 9.02 min under the conditions used. In parallel analyses, culture filtrates of B. amyloliquefaciens exhibited similar chromatographic profiles with the same prominent ions. Furthermore, the spectra obtained in the scans at this retention time were identical to those produced by authentic IAA and those previously reported

Table 1. Plant-growth-promoting activity of Bacillus amyloliquefaciens FZB42 on Lemna minor ${ }^{\mathrm{w}}$

\begin{tabular}{lcc}
\hline Conditions & Concentration & Plant growth $(\mathbf{m g} / \text { well })^{\mathbf{x}}$ \\
\hline Without bacteria $_{\text {Culture filtrate }}^{\mathrm{y}}$ & $\ldots .1 \%$ & $14.1 \pm 0.8$ \\
& $0.5 \%$ & $17.5 \pm 1.0$ \\
Growing cells $^{\mathrm{z}}$ & $2 \times 10^{5}$ & $12.0 \pm 1.4$ \\
& $1 \times 10^{7}$ & $19.3 \pm 1.2$ \\
& & $13.1 \pm 0.7$ \\
\hline
\end{tabular}

${ }^{\mathrm{w}}$ Diluted culture filtrates or growing cells were added to the Lemna plantlets. Plant growth is expressed as milligrams of plant fresh weight per well.

${ }^{\mathrm{x}}$ Mean \pm standard error from at least three independent experiments.

${ }^{\mathrm{y}}$ Concentration is expressed as the final concentration of the Bacillus culture filtrate per well.

${ }^{\mathrm{z}}$ Concentration of growing cells represents the number of bacterial cells determined as CFU added to one micro titre plate well. for IAA (Gaskin and MacMillan 1991). Thus, although no evidence of the presence of gibberellins in the extracts was found, these analyses identified the presence of IAA in B. amyloliquefaciens and suggested that IAA might act as a main component of the plant-growth-promoting activity exerted by this strain.

For IAA quantitation in the initial extractions, IAA levels in the bacterial media were estimated from peak areas. Based on these results, different amounts of $\left[{ }^{2} \mathrm{H}_{2}\right]$-IAA were added as internal standard, and the extractions were repeated until the amount of internal standards and the amount of natural IAA were approximately equal. The experiment then was repeated under these conditions to obtain accurate quantifications. First, the effect on bacterial IAA production of adding tryptophan to the media was investigated. IAA content in culture filtrates was quantified by GC-MS of the ratio of ions at m/z 202 and 204 of IAA/ $\left[{ }^{2} \mathrm{H}_{2}\right]-$ IAA, respectively. Bacteria secreted relatively high IAA amounts; even when grown without $\operatorname{Trp}\left(29.3 \mathrm{ng} \mathrm{ml}^{-1}\right)$. In culture filtrates obtained from cells grown in the presence of tryptophan, IAA production was significantly higher. Bacterial media supplemented with 0.1 and $1 \mathrm{mM}$ Trp yielded significantly different $(P<0.05)$ mean values of 51.0 and $54.0 \mathrm{ng} \mathrm{ml}^{-1}$ of IAA, while a significant fivefold stimulation of IAA production, mean value 161.0, was registered when $5 \mathrm{mM}$ Trp was added to the culture. These observations indicated that IAA production in B. amyloliquefaciens is tryptophan dependent.

This experiment also discarded hypothetical IAA contaminations of the bacterial media from plant extracts or laboratory manipulation, because IAA amounts were dependent upon Trp concentration.

\section{Disruption of tryptophan biosynthesis genes results in lower IAA synthesis.}

Production of IAA was dependent on tryptophan and strain FZB42 is genetically amenable (Koumoutsi et al. 2004); therefore, we performed knockout mutations to interrupt tryptophan biosynthesis in FZB42. Sequence analysis based on the whole genome sequence of $B$. amyloliquefaciens (Chen and Borriss; Koumoutsi et al. 2004; unpublished results) revealed complete co-linearity between the tryptophan biosynthesis gene clusters of B. subtilis (Henner and Yanofsky 1993) and FZB42 (AM295011). Function of the encoded gene products of the selected genes and their degree of similarity to B. subtilis are summarized in Table 2. Sequences containing parts of the $\operatorname{trp} A B(2.068 \mathrm{~kb})$ and $\operatorname{trpED}(2.145 \mathrm{~kb})$ genes were amplified with specific primers derived from the FZB42 genome se-

Table 2. Bacillus amyloliquefaciens FZB42 genes, possibly involved in tryptophan biosynthesis and indole-3-acetic acid (IAA) metabolism

\begin{tabular}{|c|c|c|c|c|c|c|c|c|}
\hline $\begin{array}{l}\text { Gene, } \\
\text { FZB42 } \\
\text { accession }\end{array}$ & Putative function & $\begin{array}{c}\text { EC } \\
\text { number }\end{array}$ & $\begin{array}{c}\text { Amino } \\
\text { acid } \\
\text { number }\end{array}$ & pfam & $\begin{array}{l}\text { Homologous } \\
\text { gene }\end{array}$ & Organism & Identity & Similarity \\
\hline \multicolumn{9}{|l|}{ Tryptophane ${ }^{y}$} \\
\hline & Anthranilate synthase & 4.1.3.27 & 515 & 04715 & BG10287 & $\begin{array}{l}\text { Bacillus } \\
\text { subtilis } 168\end{array}$ & $398 / 515(77 \%)$ & $445 / 515(86 \%)$ \\
\hline $\begin{array}{l}\operatorname{trpD} \\
\text { CAL26226.1 }\end{array}$ & $\begin{array}{l}\text { Anthranilate phosphoribosyl- } \\
\text { transferase }\end{array}$ & 2.4.2.18 & 338 & 02885 & BG10288 & $\ldots$ & $236 / 338(69 \%)$ & $259 / 338(76 \%)$ \\
\hline $\begin{array}{l}\text { CAL26231.1 } \\
\operatorname{trpB}\end{array}$ & Tryptophan synthase $\alpha$ chain & 4.2.1.20 & 267 & 00290 & BG10291 & $\ldots$ & $204 / 263(77 \%)$ & $227 / 263(86 \%)$ \\
\hline CAL26229.1 & Tryptophan synthase $\beta$ chain & 4.2.1.20 & 400 & 00291B & BG10290 & $\ldots$ & $337 / 400(84 \%)$ & $369 / 400(92 \%)$ \\
\hline \multirow{4}{*}{$\begin{array}{l}\text { Homologous }^{\mathrm{z}} \\
\text { ysnE, } \\
\text { CAL26203.1 } \\
\text { dhaS, } \\
\text { CAL26192.1 } \\
\text { yhcX, } \\
\text { CAL26199.1 }\end{array}$} & \multirow{4}{*}{$\begin{array}{l}\text { IAA acetyltransferase } \\
\text { NADP-dependent indole-3- } \\
\text { acetaldehyde dehydrogenase } \\
\text { Nitrilase, hydrolase carbon- } \\
\text { nitrogen family }\end{array}$} & & & & & Azospirillum & & \\
\hline & & 2.3.1.- & 151 & 00583 & P26945 & $\begin{array}{l}\text { brasilense } \\
\text { Ustilago }\end{array}$ & $51 / 148(34 \%)$ & $75 / 148(50 \%)$ \\
\hline & & 1.2.1.3 & 495 & 00171 & AAC49575 & $\begin{array}{l}\text { maydalis } \\
\text { Arabidopsis }\end{array}$ & $245 / 494(49 \%)$ & $335 / 494(67 \%)$ \\
\hline & & 3.5.5.1 & 513 & 00795 & AAB05220.1 & thaliana & $31 / 105(29 \%)$ & $49 / 105(46 \%)$ \\
\hline
\end{tabular}

\footnotetext{
${ }^{y}$ Genes involved in tryptophane biosynthesis.

${ }^{\mathrm{z}}$ Genes homologous to genes involved in IAA biosynthesis.
} 
quence. Disruption of the respective genes was achieved by insertion of an antibiotic resistance cassette via homologous recombination, leading to replacement of the wild-type gene via double crossover as previously described (Chen et al. 2006; Koumoutsi et al. 2004). Resulting transformants were confirmed by Southern hybridization and found to be unable to grow in minimal medium without tryptophan. When both trp mutant strains, E101 ( $\triangle t r p E D)$ and E102 ( $\triangle t r p A B)$, were analyzed by GC-MS for the presence of IAA in their culture filtrates, a distinct reduction of IAA production was observed. Quantification revealed that both mutant strains produced less plant hormone than the wild-type strain. Strain E101 bearing the knockout mutation affecting the early steps of Trp biosynthesis (Table 3 ) produced only $15 \%$ of the wild-type strain IAA levels, indicating that the main route of IAA production in $B$. amyloliquefaciens is dependent on tryptophan biosynthesis.

\section{IAA concentration in strains with knockout mutations} in genes bearing homology to IAA biosynthesis genes.

Several routes of tryptophan-dependent IAA biosynthesis in microorganisms are known (Fig. 1); however, no gene products involved in IAA biosynthesis in gram-positive bacteria have been identified thus far. Examination of the whole-genome sequence of $B$. amyloliquefaciens FZB42 revealed three candidate genes with apparent homology to genes previously reported to be involved in IAA metabolism: ysnE, encoding a protein similar to the IAA acetyltransferase from Azospirillum brasilense (Zimmer et al. 1991); dhaS, similar to indole-3-acetaldehyde dehydrogenase from Ustilago maydalis (Basse et al. 1996); and $y h c X$, encoding a putative nitrilase similar to nitrilase2 from Arabidopsis thaliana (Hillebrand et al. 1998). All three genes have counterparts in the genome of B. subtilis 168 (Kunst et al. 1997). Properties of the deduced gene products, identity, and similarity scores are summarized in Table 2.

The respective genes were inactivated by the gene replacement technique as described above. Amplification of $y s n E$, $d h a S$, and $y h c X$ gene sequences was performed with sequencespecific primers designed according to the sequence information from AM295009 (ysnE containing region), AM295008 (dhaS containing region), and AM295010 (yhcX containing region) (Table 4). Integrative plasmids unable to replicate in Bacillus spp. and bearing the respective gene sequences interrupted by an antibiotic cassette were transformed after lineari- zation into competent B. amyloliquefaciens FZB42 cells. Transformants expressing the resistance marker after integration of the corresponding homologous flanking sequences within the chromosome via double crossover were analyzed by Southern hybridization.

Quantification of the IAA amounts present in culture filtrates of strains E103 $(\Delta y s n E)$ and E105 $(\Delta y h c X)$ by the GC-MS methodology revealed reduced amounts of IAA. The $\Delta y s n E$ mutant strain formed only $28 \%$ of the amount produced by the wild type, while the strain bearing the mutation $\Delta y h c X$ produced half of the amount of the wild type. Strain E104 ( $\Delta d h a S)$ was not significantly affected in its IAA production, suggesting no participation of the dhaS gene product in IAA synthesis (Table 5).

\section{Survey of plant-growth-promoting activities in mutant strains revealed dependency on IAA production.}

The Trp-auxotrophic mutant strains E101 ( $\triangle$ trpED) and E102 $(\triangle \operatorname{trp} A B)$ were analyzed for plant-growth-promoting activity in the Lemna test system as described above. Direct application of growing bacteria resulted in only a slight increase of plant fresh weight compared with the untreated control, whereas addition of diluted culture filtrates obtained from both trp mutant strains did not result in any promotion of plant growth. The strong reduction in or abolition of plant-growthpromoting activity in both trp mutants may be due to the severe reduction of IAA excretion in those strains (Table 5).

Strain E103 bearing the $\triangle y s n E$ mutation was impaired in its capability to support plant growth. This is in line with our hypothesis that IAA production is closely linked with plant growth promotion. Strain E104 ( $\Delta d h a S)$, producing nearly as much IAA as the wild type, retained its ability to promote plant growth. However, strain E105 ( $\Delta y h c X)$, forming approximately $50 \%$ IAA compared with the wild type, still was able to stimulate plant growth to the same extent as the wild type. The level of IAA produced by this strain is probably still above the critical threshold for supporting plant growth (Table 5). Alternatively, this observation is compatible with the notion that the promotion of plant growth may be due not only to the amount of bacterial IAA but also to the additional IAA converted by the Lemna nitrilase from the accumulated indole 3-acetonitrile excreted by the bacterium after blockage of IAA formation due to the knockout of the $y h c X$ gene product.

Table 3. Bacterial strains and plasmids used

\begin{tabular}{|c|c|c|}
\hline Strain or plasmid & Description $^{\mathrm{z}}$ & Source or reference \\
\hline \multicolumn{3}{|l|}{ Escherichia coli } \\
\hline DH5 $\alpha$ & supE44, AlacU169 ( $\$ 80$ lacZ M15) hsdR17 recA1 gyrA96 thi-1 relA91 endA1 & Lab strain \\
\hline \multicolumn{3}{|c|}{ 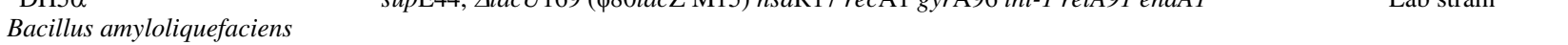 } \\
\hline FZB42 & Wild-type isolate & BGSC 10A6 \\
\hline E101 & $\triangle \operatorname{trp} A B:: \mathrm{Em}^{\mathrm{r}}$ & $\mathrm{pEI} 2 \rightarrow \mathrm{FZB} 42$ \\
\hline E102 & $\triangle \operatorname{trpED}:: \mathrm{Em}^{\mathrm{r}}$ & $\mathrm{pEI} 4 \rightarrow \mathrm{FZB} 42$ \\
\hline E103 & $\Delta y \operatorname{sn} n:: \mathrm{Em}^{\mathrm{r}}$ & pEI6 $\rightarrow$ FZB42 \\
\hline E104 & $\Delta d h a S:: \mathrm{Em}^{\mathrm{r}}$ & pEI8 $\rightarrow$ FZB42 \\
\hline E105 & $\Delta y h c X:: \mathrm{Em}^{\mathrm{r}}$ & pEI10 $\rightarrow$ FZB42 \\
\hline \multicolumn{3}{|l|}{ Plasmids } \\
\hline $\mathrm{pGEM}^{\mathrm{R}}-\mathrm{T}$ & Cloning vector $\mathrm{Amp}^{\mathrm{r}}$, lac $\mathrm{Z}^{\prime}$ & Promega \\
\hline pEI1 & pGEMT containing $2.06 \mathrm{~kb}$ insert of $\operatorname{trp} A B$ & This work \\
\hline $\mathrm{pEI} 2$ & pEI1 with $\operatorname{trp} A B \therefore \mathrm{em}^{\mathrm{r}}$ insertion & This work \\
\hline pEI3 & pGEMT containing $2.14 \mathrm{~kb}$ insert of $\operatorname{trp} E D$ & This work \\
\hline pEI4 & pEI3 with $\operatorname{trpED~}: \because \mathrm{em}^{\mathrm{r}}$ insertion & This work \\
\hline pEI5 & pGEMT containing 1.94-kb insert of $y s n E$ & This work \\
\hline pEI6 & pEI5 with ysnE ::em ${ }^{\mathrm{r}}$ insertion & This work \\
\hline pEI7 & pGEMT containing $2.633-\mathrm{kb}$ insert of $d h a S$ & This work \\
\hline pEI8 & pEI7 with dhaS::em ${ }^{\mathrm{r}}$ insertion & This work \\
\hline pEI9 & pGEMT containing $1.9-\mathrm{kb}$ insert of $y h c X$ & This work \\
\hline pEI10 & pEI9 with $y h c X:: e m^{\mathrm{r}}$ insertion & This work \\
\hline
\end{tabular}

${ }^{\mathrm{z}} \mathrm{Em}^{\mathrm{r}}=$ erythromycin resistant and $\mathrm{Amp}^{\mathrm{r}}=$ ampicillin resistant. 


\section{DISCUSSION}

Plant-growth-promoting activity of $B$. amyloliquefaciens FZB42 and of some other strains belonging to the B. subtilis/ B. amyloliquefaciens group is well documented (Bochow et al. 2001; Grosch et al. 1999; Idriss et al. 2002; Schmiedeknecht et al. 1998; Yao et al. 2006). In our previous study (Idris et al. 2004), we demonstrated that, in the presence of diluted $B$. amyloliquefaciens culture filtrates, elongation growth of maize seedlings was significantly enhanced. Moreover, strong curvature, obtained after application of bacterial culture filtrates on maize coleoptiles, indicated the presence of an auxin (IAA)-like compound in the supernatant of FZB42. However, the chemical nature of the compound or compounds responsible for the phytohormone-like action was not uncovered, although traces of material reacting with IAA-specific antibodies were detected in the bacterial culture filtrate.

Here, we successfully established a miniaturized biotest system enabling us to compare the phytostimulatory effects exerted by FZB42 wild-type and mutant strains. A selected clone from duck weed, L. minor ST, the smallest flower plant known, was shown to react to plant-growth-promoting effects exerted by the PGPR B. amyloliquefaciens FZB42. The duck weed clone was cultured for decades in the laboratory, was easy to handle, and yielded reproducible results in plant growth test assays. Using this system, we corroborated our earlier results about plant growth promotion exerted by diluted FZB42 culture filtrates. Moreover, we have now demonstrated that a strong plantgrowth-promoting effect occurs in vivo when growing FZB42 cells are added directly to duckweed fronds.

For the first time, we have shown that the gram-positive bacterium $B$. amyloliquefaciens is able to produce and secrete significant amounts of IAA, whereas production of gibberellin was not detected by our GC-MS approach. Increased IAA production after addition of tryptophan and drastic reduction of IAA production in engineered trp mutants suggested that the main route of IAA biosynthesis in this bacterium is dependent on tryptophan. Stimulation of IAA synthesis by tryptophan was described previously for gram-negative plantassociated bacteria (Ernsten et al. 1987; Koga et al. 1991). Patten and Glick (2002) used a mutant of the gram-negative plant-beneficial bacterium Pseudomonas putida, deficient in

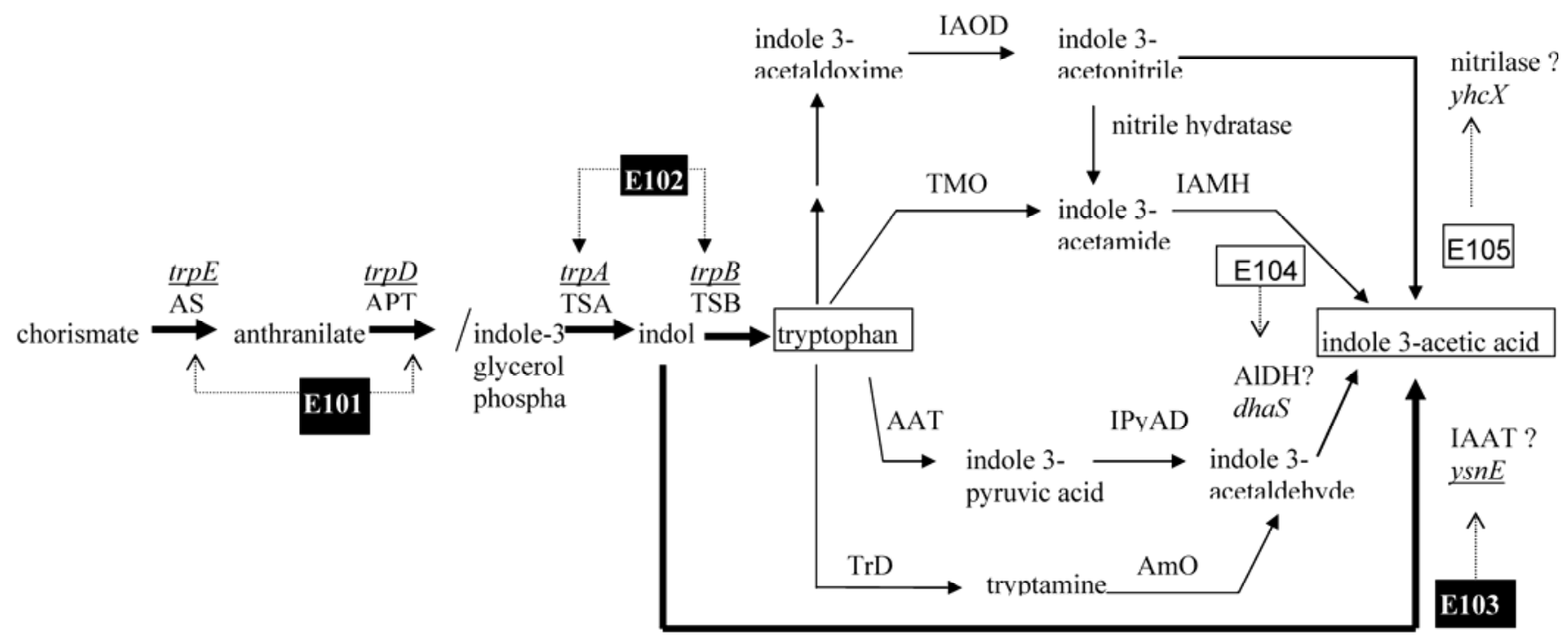

Fig. 1. Tryptophan-dependent pathways of bacterial indole-3-acetic acid (IAA) synthesis compiled from Patten and Glick (1996) and Steenhoudt and Vanderleyden (2000). The following enzymes were proposed to be involved in bacterial tryptophan-dependent IAA biosynthesis: AS, anthranilate synthase (trpE); APT, anthranilate phosphoribosyltransferase (trpD); TSA, tryptophan synthase (trpAB); AAT, tryptophan transaminase; IPyAD, indole-3-pyruvate decarboxylase (ipdc); AIDH, indole-3-acetaldehyde dehydrogenase (dhaS); TrD, tryptophan decarboxylase; AmO, amine oxidase; IAAT, IAA transacetylase ( $y s n E)$; TMO, tryptophan 2-monoxygenase; IAMH, indole-3-acetamide hydrolase; nitrile hydratase; and nitrilase $(y h c X)$. The $\alpha$-subunit of the tryptophan synthase catalyzes the conversion of 1-(indol-3-yl)glycerol 3-phosphate to indole and glyceraldehyde 3-phosphate. The indole then migrates to the $\beta$-subunit where, with serine in the presence of pyridoxal 5'-phosphate, it is converted to tryptophan. It also catalyses the conversion of serine and indole to tryptophan and water, and of indole glycerol phosphate into indole and glyceraldehyde phosphate. Reactions probably occurring in Bacillus. amyloliquefaciens FZB42 are indicated by bold arrows. The genes knocked out in this study are shown in italics and the respective mutant strains are framed. Underlined genes indicate that the generated knockout mutants produced 50\% less IAA than wild type. Filled boxes indicate lowered IAA production accompanied by significant reduction of plant-growth-promoting activity (E101, E102, and E103).

Table 4. Primers used in this study

\begin{tabular}{|c|c|c|c|c|c|}
\hline Primer & Sequence $\left(5^{\prime} \rightarrow 3^{\prime}\right)$ & $\begin{array}{c}\text { Position in DNA } \\
\text { sequence }\end{array}$ & Accession number & $\begin{array}{c}\begin{array}{c}\text { Size of DNA } \\
\text { sequence (bp) }\end{array} \\
\end{array}$ & Gene \\
\hline $\operatorname{trpBA}-1$ & AGCTGAATTCTTTCACCTTACG & $8,543 \ldots 8,564$ & AM295011 & 12,335 & $\operatorname{trpBA}$ \\
\hline $\operatorname{trpBA}-2$ & AGATGGCTCAATTTGCACC & $6,496 \ldots 6,514$ & $\ldots$ & $\ldots$ & $\operatorname{trp} B A$ \\
\hline trpED-1 & TACAAATCCGGCAAGCTCCTC & $4,534 \ldots 4,554$ & $\ldots$ & $\ldots$ & $\operatorname{trpED}$ \\
\hline trpED-2 & TGATATCCATTCCGTATTTCCG & $2,410 \ldots 2,431$ & & . & $\operatorname{trpED}$ \\
\hline dhaS-1 & AACGATCCGTCCGGTCGCCGGCTC & $810 \ldots 830$ & AM295008 & 4,697 & dhas \\
\hline dhaS-2 & ATGACTAAGAAAGATAATGGCAG & $2,429 \ldots 2,407$ & & & dhas \\
\hline ysnE-1 & TCAAAAGCAGATTCACATCTTCCC & $1,664 \ldots 1,641$ & AM295009 & 3,253 & $y s n E$ \\
\hline ysnE-2 & AGAGGGGTGTTGCGCTTGCG & $213 \ldots 232$ & & & $y s n E$ \\
\hline nit-1 & ATTGTTTTCCGGGGATGGAGCC & $1,856 \ldots 1,877$ & AM295010 & 5,485 & $y h c X$ \\
\hline nit-2 & ATGCCGTCCAAATACCGTCTGCC & $3,707 \ldots 3,685$ & $\ldots$ & $\ldots$ & $y h c X$ \\
\hline
\end{tabular}

${ }^{\mathrm{z}}$ Accession numbers of the DNA sequences used for design of appropriate primer sequences is indicated. 
the ipdc gene product (indole-3-pyruvate decarboxylase), to demonstrate that IAA synthesis in bacteria is dependent on tryptophan concentration.

Because gene products involved in IAA metabolism in gram-positive bacteria are completely unknown, we applied a genomic approach, taking advantage of the whole genome sequence of B. amyloliquefaciens (Koumoutsi et al. 2004). Only three genes with apparent homology to genes already known to be involved in IAA biosynthesis in other organisms were detected. Mutants bearing $\triangle y s n E$ and $\Delta y h c X$ deletions were found impaired in IAA production. The deduced $y h c X$ gene product is similar to nitrilase 2 of Arabidopsis thaliana, which catalyzes the direct conversion of indole 3 -acetonitrile to IAA (Hillebrand et al. 1998). The $y s n E$ gene is similar to a putative IAA acetyl transferase gene localized within the tryptophan biosynthesis gene cluster of the plant-growth-promoting $\alpha$ proteobacterium Azospirillum brasilense (Zimmer et al. 1991). Its deduced gene product belongs to a widely distributed family of acetyl transferases (acetyltransf._1) that catalyze the transfer of an acetyl group to a nitrogen atom on the acceptor molecule. YsnE has been suggested to participate in the tryptophandependent IAA production (Zimmer et al. 1991). Taken together, the results present additional evidence for the existence of a tryptophan-dependent pathway as the main route of IAA biosynthesis in B. amyloliquefaciens FZB42. However, minor tryptophan-independent pathways for IAA biosynthesis may exist in FZB42, because IAA biosynthesis was not abolished completely in the trp, $y s n E$, and $y h c X$ mutant strains. Double mutants might be useful to prove the presence of alternative Trp-independent pathways.

As with plants, decarboxylation and deamination of tryptophan seem to be the preferred routes in bacterial IAA metabolism (Normanly and Bartel 1999). Phytopathogenic and plantbeneficial gram-negative bacteria synthesize IAA by Trp-dependent pathways with indole-3-pyruvic acid (IPA), indole-3acetamide (IAM), or indole-3-acetonitrile (IAN) as important intermediates (Kobayashi et al. 1995; Koga et al. 1991; Magie et al. 1963; Patten and Glick 1996) (Fig. 1). IAA synthesis in gram-positive bacteria has been detected in Paenibacillus polymyxa (Lebuhn et al. 1997) and investigated in more detail in the phytopathogenic Rhodococcus fascians. The main biosynthetic route for IAA in this bacterium is the IPA pathway, with a possible rate-limiting role for indole-3-ethanol (Vandeputte at. 2005). The results presented here do not support such a scenario for IAA metabolism in B. amyloliquefaciens. The knockout mutant with a destroyed function of the dhaS gene was not impaired in IAA biosynthesis in FZB42. DhaS is similar to aldehyde dehydrogenase, probably catalyzing the last reaction of the indole-pyruvic acid pathway converting indole-3-acetaldehyd to IAA in $U$. maydalis (Basse et al. 1996). No gene products similar to the key enzymes of the IPA pathway, indole pyruvate decarboxylase (IPDC) and tryptophan transaminase (converting tryptophan to indole-3-pyruvic acid) (Patten and Glick 1996), were detected during our analysis of the wholegenome sequence of FZB42. Genes with similarity to Trp monoxygenase (TMO) and to indole-3-acetamide hydrolase (IAMH) catalyzing both reactions of the IAM pathway could not be detected. Therefore, feeding experiments will be necessary to uncover the metabolic route for tryptophan-dependent IAA synthesis in FZB42, and the roles of the reactions catalyzed by the $y s n E$ and $y h c X$ gene products in IAA biosynthesis remain to be elucidated.

When mutant strains ( $\triangle \operatorname{trpDE}, \triangle \operatorname{trp} A B$, and $\triangle y s n E)$ with low IAA synthesis capacity were added to duckweed fronds, plant-growth-promoting effects decreased, demonstrating a close correlation of plant growth promotion and auxin production in FZB42. It is likely that tryptophan-like compounds present in plant exudates stimulate IAA synthesis of the PGPR colonizing plant surface structures. In fact, our successful attempts to reisolate $B$. amyloliquefaciens directly from L. minor plantlets (E. E. Idris and R. Borriss, unpublished) indicates that the bacteria living in close vicinity to the plant surface can uptake excreted plant compounds. Recently, it has been shown that one of the main compounds present in some plant exudates is L-tryptophan (Kamilova et al. 2006). One could speculate that stimulated bacterial IAA production in the presence of the IAA precursor tryptophan will lead vice versa to further promotion of plant growth, suggesting a close symbiotic relationship between the plant and colonizing FZB42. Simultaneously, these findings provide a possible explanation for the remarkably high rhizosphere competence observed in FZB42 growing on tomato seedlings (Cadena-Cepeda et al. 2006). The ability to colonize plant roots may depend to some degree on the capability of the bacterium to synthesize IAA. It has been proposed that bacterial IAA synthesis contributes to enhanced rhizosphere competence by i) detoxification of Trp analogues present on host plant surfaces (Lebuhn et al. 1997) and ii) stimulation of the release of plant exudates (Lambrecht et al. 2000), the downregulation of plant defense (Yamada 1993), or the inhibition of the hypersensitive response of infected plants (Robinette and Matthysse 1990). However, further experiments are necessary to confirm such a scenario in the case of B. amyloliquefaciens.

In conclusion, the results presented here elucidate the role of Trp-dependent IAA synthesis within the spectrum of the diverse, mainly unknown molecular effects exerted by root-colonizing bacilli on plant growth.

\section{MATERIALS AND METHODS}

\section{Strains and growth conditions.}

Bacterial strains used in this study are listed in Table 3. B. amyloliquefaciens FZB42 was deposited as strain 10A6 in the culture collection of the Bacillus Genetic Stock Center. Bacteria were cultivated routinely in Luria broth (LB) solidified with $1.5 \%$ agar. For IAA production, the bacteria were grown for $72 \mathrm{~h}$ in Landy medium (Landy et al. 1948) at $25^{\circ} \mathrm{C}$ and 75 rpm (Idris et al. 2004). Mutant strains deficient in Trp biosynthesis routinely were grown in the presence of Trp at $20 \mu \mathrm{g} / \mathrm{ml}$. The duckweed clone L. minor ST originally was isolated by Pirson and Seidel (1950) and was delivered from the culture collection of the Botanical Institute of the University of Jena, Germany.

Table 5. Effect of knockout mutations on indole-3-acetic acid (IAA) production and plant growth promoting activity ${ }^{\mathrm{z}}$

\begin{tabular}{lcc}
\hline & \multicolumn{2}{c}{ Percentage of wild type } \\
\cline { 2 - 3 } Genotype & IAA production & Growth promotion \\
\hline E101 $\Delta \operatorname{trpED}:: \mathrm{Em}^{\mathrm{r}}$ & $14.7 \mathrm{~d}$ & $16.8 \mathrm{~b}$ \\
E102 $\Delta t r p B A:: \mathrm{Em}^{\mathrm{r}}$ & $38.0 \mathrm{c}$ & $19.2 \mathrm{~b}$ \\
E103 $\Delta y \sin :: \mathrm{Em}^{\mathrm{r}}$ & $28.9 \mathrm{c}$ & $19.1 \mathrm{~b}$ \\
E104 $\Delta$ dhaS $:: \mathrm{Em}^{\mathrm{r}}$ & $71.2 \mathrm{a}$ & $71.0 \mathrm{a}$ \\
E105 $\Delta y h c X:: \mathrm{Em}^{\mathrm{r}}$ & $51.4 \mathrm{~b}$ & $81.5 \mathrm{a}$ \\
\hline
\end{tabular}

${ }^{\mathrm{z}}$ IAA concentration was determined after growth in Landy medium without Trp except the two trp mutants cultivated in the presence of Trp at the rate of $20 \mu \mathrm{gml}$. Abundance of IAA was calculated through gas chromatography-mass spectrometry quantitation of the area ratio of ions at $\mathrm{m} / \mathrm{z} 202$ and 204 of IAA $/\left[{ }^{2} \mathrm{H}_{2}\right]$-IAA, respectively. Plant growth promotion was assayed in the Lemna minor test system, using $2 \times 10^{5}$ cells per well. Diluted culture filtrates (final concentration of $0.1 \%$ ) from trpminus mutants did not significantly affect growth of Lemna plants. $\mathrm{Em}^{\mathrm{r}}=$ erythromycin resistant. Data are means and different letters in the same column indicate significant differences $(P<0.05)$. 
Preparation of competent $B$. amyloliquefaciens FZB42 cells and DNA transformation.

Competent cells of $B$. amyloliquefaciens were obtained by modifying the two-step protocol of Kunst and Rapoport (1995). Cells were grown overnight in LB medium at $28^{\circ} \mathrm{C}$ (170 rpm) and were diluted the next day in GCHE medium containing $1 \%$ glucose, $0.2 \%$ potassium L-glutamate, $100 \mathrm{mM}$ potassium phosphate buffer ( $\mathrm{pH} 7), 3 \mathrm{mM}$ trisodium citrate, 3 $\mathrm{mM} \mathrm{MgSO} 4,22 \mathrm{mg}$ of ferric ammonium citrate per liter, 50 mg L-typtophan per liter, and $0.1 \%$ casein hydrolysate, to an optical density at $600 \mathrm{~nm}\left(\mathrm{OD}_{600}\right)$ of 0.3 . The cell culture then was incubated at $37^{\circ} \mathrm{C}$ under vigorous shaking (200 rpm) to midexponential growth $\left(\mathrm{OD}_{600}\right.$ of approximately 1.4). Dilution with an equal volume of GC medium (GCHE medium without potassium glutamate and casein hydrolysate) followed and the cells were incubated further under the same conditions for $1 \mathrm{~h}$. The culture then was divided into two tubes and cells were harvested by centrifugation at $6,000 \mathrm{rpm}$ for $5 \mathrm{~min}$ (room temperature). Afterwards, the pellets were resuspended in $200 \mu \mathrm{l}$ of the supernatant and $1 \mu \mathrm{g}$ of DNA in $2 \mathrm{ml}$ of transformation buffer consisting of $15 \mathrm{mM}(\mathrm{NH} 4)_{2} \mathrm{SO}_{4}, 80 \mathrm{mM} \mathrm{K} \mathrm{HPO}_{4}, 45$ $\mathrm{mM} \mathrm{H}_{2} \mathrm{KPO}_{4}, 35 \mathrm{mM}$ sodium citrate, $1 \mathrm{mM}$ EGTA, $25 \mathrm{mM}$ glucose, and $30 \mathrm{mM} \mathrm{MgCl} 2$. After incubation at $37^{\circ} \mathrm{C}$ under shaking at $75 \mathrm{rpm}$ for $20 \mathrm{~min}, 1 \mathrm{ml}$ of LB medium containing a sublethal concentration $(0.1 \mu \mathrm{g} / \mathrm{ml})$ of the appropriate antibiotic was added. The cells were grown under vigorous shaking for $90 \mathrm{~min}$ and plated on selective agar plates. For selection of erythromycin-resistant transformants, erythromycin at $1 \mu \mathrm{g} / \mathrm{ml}$ and lincomycin at $25 \mu \mathrm{g} / \mathrm{ml}$ were added to the selection plates.

\section{The Lemna biotest system.}

L. minor ST was propagated axenically in filter-sterilized $(0.45$ to $0.2 \mu \mathrm{m})$ Steinberg medium adjusted to $\mathrm{pH}$ 5.5. The growth medium consisted of the following components: 3.46 $\mathrm{mM} \mathrm{KNO} 3,1.25 \mathrm{mM} \mathrm{Ca}\left(\mathrm{NO}_{3}\right)_{2} \cdot \mathrm{H}_{2} \mathrm{O}, 0.66 \mathrm{mM} \mathrm{KH}_{2} \mathrm{PO}_{4}$, $0.072 \mathrm{mM} \mathrm{K}{ }_{2} \mathrm{HPO}_{4}, 0.41 \mathrm{mM} \mathrm{MgSO}{ }_{4}, 1.94 \mu \mathrm{M} \mathrm{H}_{3} \mathrm{BO}_{3}, 0.63$ $\mu \mathrm{M} \mathrm{ZnSO}_{4} \cdot 7 \mathrm{H}_{2} \mathrm{O}, 0.18 \mu \mathrm{M} \mathrm{Na}_{2} \mathrm{MoO}_{4} \cdot 2 \mathrm{H}_{2} \mathrm{O}, 0.91 \mu \mathrm{M}$ $\mathrm{MnCl}_{2} \cdot 4 \mathrm{H}_{2} \mathrm{O}, 2.81 \mu \mathrm{M} \mathrm{FeCl} \cdot 6 \mathrm{H}_{2} \mathrm{O}$, and $4.03 \mu \mathrm{M}$ EDTA. Under aseptic conditions, four plants with two to three budding-pouches (fronds) were incubated in $200 \mathrm{ml}$ of medium in a $500 \mathrm{ml}$-conical flask. Flasks were kept at $20^{\circ} \mathrm{C}$ with continuous light until a sufficient number of homogenous Lemna plants were obtained. The growth medium was changed each week. To prove the bioeffects of FZB42 and its derivatives on Lemna spp. growth, a model test system based on duckweed growing in 48-well microtiter plates was developed. Each well contained $1.2 \mathrm{ml}$ of Steinberg minimal medium. Standardized Lemna plants possessing two fronds were transferred aseptically into every well of the microtiter plate. Culture filtrates or bacteria in appropriate dilutions were added directly. Each variant was performed in six replicates. The microtiter plates were kept at $20^{\circ} \mathrm{C}$ and $24 \mathrm{~h}$ of light for 10 days. Plants were harvested and growth was determined by determination of fresh weight and frond number. The result of each trial was confirmed by four repetitions.

\section{Construction of plasmids and strains.}

In order to replace the respective wild-type genes, appropriate gene cassettes consisting of the erythromycin resistance determinant flanked by the respective gene sequences were constructed (Table 1). Primers for amplification of chromosomal DNA sequences were designed according to sequence information obtained from the sample genome sequence of B. amyloliquefaciens as previously reported (Koumoutsi et al. 2004) (Table 4). Briefly, the amplified sequences were cloned into the pGEMT vector. A unique restriction site located within the central part of the coding region was used to interrupt the gene se- quence by insertion of the ermAM resistance determinant isolated from plasmid pDB101 (Ceglowski and Alonso 1994).

\section{Identification and quantification of IAA by GC-MS.}

Extraction and purification. Culture filtrates of FZB42 and its Trp-minus mutants, produced in Landy medium under specific conditions, at $22^{\circ} \mathrm{C}$ and $75 \mathrm{rpm}$ in the dark (Idris et al. 2004), were used for plant hormone identification. Extractions were performed with $80 \%$ methanol. After purification with SS-Sax and $\mathrm{C}_{18}$ Sep-Pak cartridges (Talon et al. 1990), samples were dried to vacuum until further fractionation with reversephase HPLC. Abscisic acid $(1 \mu \mathrm{g})$ then was added as an internal standard to ascertain the reproducibility of retention times. Samples were filtered through a $0.45-\mu \mathrm{m}$-diameter nylon filter and were injected into a Waters high-performance liquid chromatograph. The instrument was equipped with an analytical column ( 25 by $0.46 \mathrm{~cm}$ i.d.) packed with Hypersil $\mathrm{C} 18$ and attached to a C18 Guard-Pak precolumn. A 40-min linear gradient of 20 to $100 \%$ methanol in $1 \%$ aqueous acetic acid at a flow rate of $1 \mathrm{ml} \mathrm{min}^{-1}$ was used. The HPLC fractions were collected at l-min intervals and conveniently grouped. Samples were evaporated to dryness, methylated with ethereal diazomethane, and trimethylsilylated at room temperature for at least 1 $\mathrm{h}$ with 5 to $10 \mu \mathrm{l}$ of. bis-trimethylsilyl-triftuoroacetamide.

Identification. All HPLC fractions were analyzed by GC-MS using a gas chromatograph (Star 3400 CX; Varian, Sunnyvale, CA, U.S.A.) coupled to an ion trap mass spectrometer (Saturn 3; Varian). The samples $(1 \mu \mathrm{l})$ were co-injected automatically with an autosampler (8200 CX; Varian) in the splitless mode into a fused silica capillary column $(30 \mathrm{~m}$ by $0.25 \mathrm{~mm}$ by 0.25 $\mu \mathrm{m}$ of film thickness) (DB5MS; J\&W Scientific, Folsom, CA, U.S.A.). The oven temperature was $50^{\circ} \mathrm{C}$ and, after $1 \mathrm{~min}$, was increased at $30^{\circ} \mathrm{C} \mathrm{min}{ }^{-1}$ to $240^{\circ} \mathrm{C}$ and then at $10^{\circ} \mathrm{C} \mathrm{min}-1$ to $280^{\circ} \mathrm{C}$. The He inlet pressure was $60 \mathrm{kPa}$ and the injector, interface and manifold temperatures were 280,290 , and $170^{\circ} \mathrm{C}$, respectively. Other operating parameters were as described by Ben-Cheikh and associates (1997). For hormone identification, full-scan positive ion-electron-impact mass spectra were acquired scanning from 100 to $600 \mathrm{amu}$ at $1 \mathrm{~s}$ per scan cycle, a range including spectra of most acidic plant growth regulators, such as indole-acetic acid and gibberellins. IAA production was verified by comparing HPLC elution volumes, KRIs (Kovats retention indices), and mass spectra with those of authentic IAA and published data (Gaskin and MacMillan 1991).

Quantitation. For quantitation purposes, $\left[{ }^{2} \mathrm{H}_{2}\right]-\mathrm{IAA}$ was added to the extracts as an internal standard and the above procedures for extraction, purification, and GC-MS analyses were repeated. Abundance of IAA was monitored through calculation of the area ratio of ions at m/z 202 and 204 of IAA $/\left[{ }^{2} \mathrm{H}_{2}\right]-$ IAA, respectively, in the chromatographic profiles. In preliminary analyses, various amounts of internal standards were added to the extracts in consecutive extractions and, thus, the produced IAA amounts initially were estimated. This strategy was repeated until the amount of internal standards and the amount of endogenous IAA was approximately equal, which is a requirement of the calculation method (Talon and Zeevaart 1992). Once the amount of internal standard to be added was established, final determinations on independent extractions were carried out (Mehouachi et al. 2000). In these final quantitations, several injections that provided near-identical results for each sample were performed. All quantitations were repeated independently on at least two different culture replicates and only averages of these final quantitations are presented.

\section{Nucleotide sequence accession numbers.}

The GenBank accession numbers for the B. amyloliquefaciens FZB42 typtophan biosynthetic gene cluster and the DNA 
fragments containing the $d h a S$ gene, the $y s n E$ gene, and the $y h c X$ gene are AM295011, AM295008, AM295009, and AM295010, respectively.

\section{ACKNOWLEDGMENTS}

Partial financial support given for the genomic network sponsored by BMBF, the German Ministry for Education and Research, is gratefully acknowledged. E. E. Idris is indebted to A. von Humboldt (Stiftung, Bonn, Germany) for the financial support given during her research stay in Germany. Funding from INIA through grant RTA04-013 to M. Talon is also gratefully acknowledged. We would like to thank K.-J. Appenroth (University of Jena, Germany), who kindly provided us with the Lemna minor St. clone, and LemnaTec GmbH (Würselen, Germany), for generously providing us with information and advice for the appropriate handling of the model plant. S. Porwollik (Sidney Kimmel Cancer Center, San Diego, CA, U.S.A.) and T. Buckhout are especially thanked for valuable hints for improving the manuscript.

\section{LITERATURE CITED}

Basse, C. W., Lottspeich, F., Steglich, W., and Kahmann, R. 1996. Two potential indole-3-acetaldehyde dehydrogenases in the phytopathogenic fungus Ustilago maydis. Eur. J. Biochem. 2242: 648-656.

Ben-Cheikh W., Pérez-Botella, J., Tadeo F. R., Talon M., and Primo-Millo E. 1997. Pollination increases gibberellin levels in developing ovaries of seeded varieties of citrus. Plant Physiol. 114: 557-564.

Bloemberg, G. V., and Lugtenberg, B. J. 2001. Molecular basis of plant growth promotion and biocontrol by rhizobacteria. Curr. Opin. Plant Biol. 4:343-350.

Bochow, H., El-Sayed, S. F., Junge, H., Stavropoulo, A., and Schmiedeknecht, G. 2001. Use of Bacillus subtilis as biocontrol agent. IV. Saltstress tolerance induction by Bacillus subtilis FZB24 seed treatment in tropical vegetable field crops, and its mode of action. J. Plant Dis. Prot. 108:21-30.

Bottini, R., Cassán, F., and Piccoli, P. 2004. Gibberellin production by bacteria and its involvement in plant growth promotion and yield increase. Appl. Microbiol. Biotechnol. 65:497-503.

Cadena-Cepeda, M., Kokalis-Burelle, N., Runion, G. B., and Kloepper, J. W. 2006. Assessing soil microbial populations and enzyme activity following the use of microbial inoculants. In: 7th Int. Workshop Plant Growth Promoting Rhizobacteria, Noordwijkerhoot, The Netherlands.

Ceglowski, P., and Alonso, J. C. 1994. Gene organisation of the Streptococcus pyogenes plasmid pDB101: Sequence analysis of the OR FetacopS region. Gene 145:33-39.

Chen, X.-H., Vater, J., Piel, J., Franke, P., Scholz, R., Schneider, K., Koumoutsi, A., Hitzeroth, G., Grammel, N., Strittmatter, A. W., Gottschalk, G., Süssmuth, R., and Borriss, R. 2006. Structural and functional characterization of three polyketide synthase gene clusters in $\mathrm{Ba}$ cillus amyloliquefaciens FZB 42. J. Bacteriol. 188:4024-4036.

Emmert, E. A. B., and Handelsman, J. 1999. Biocontrol of plant disease: A Gram-positive perspective. FEMS (Fed. Eur. Microbiol. Soc.) Microbiol. Lett. 171:1-9.

Ernsten, A., Sandberg, G., Crozier, A., and Wheeler, C.T. 1987. Endogenous indoles and the biosynthesis and metabolism of indole-3-acetic acid in cultures of Rhizobium phaseoli. Planta 171:422-428.

Gaskin, P., and J. MacMillan. 1991. Discussion of spectra of TMSi ester TMSi ethers. In: GC-MS of the Gibberellin and Related Compounds: Methodology and a Library of Spectra. P. Gaskin and J. MacMillan, eds. Cantocks Enterprises Ltd., University of Bristol, Bristol, U.K.

Grosch, R., Junge, H., Krebs, B., ad Bochow, H. 1999. Use of Bacillus subtilis as biocontrol agent. III. Influence of Bacillus subtilis on fungal root diseases and on yield in soilless culture. J. Plant Dis. Prot. 106:568-580

Gutierrez-Mañero, F. J., Ramos-Solano, B., Probanza, A., Mehouachi, J., Tadeo, F. R., and Talon, M. 2001. The plant-growth-promoting rhizobacteria Bacillus pumilus and Bacillus licheniformis produce high amounts of physiologically active gibberellins. Physiol. Plant. 111:206-211.

Henner, D., and Yanofsky, C. 1993. Biosynthesis of aromatic amino acids. Pages 269-280 in: Bacillus subtilis and Other Gram-Positive Bacteria. A. L. Sonenshein, J. A. Hoch, and R. Losick, eds. American Society for Microbiology, Washington, D.C.

Hillebrand, H., Bartling, D., and Weiler, E. W. 1998. Structural analysis of the nit2/nit1/nit3 gene cluster encoding nitrilases, enzymes catalyzing the terminal activation step in indole-acetic acid biosynthesis in Arabidopsis thaliana. Plant Mol. Biol. 36:89-99.

Idris, E. E. S., Bochow, H., Ross, H., and Borriss, R. 2004. Use of Bacillus subtilis as biocontrol agent. VI. Phytohormone like action of culture fil- trates prepared from plant growth-promoting Bacillus amyloliquefaciens FZB24, FZB42, FZB45 and Bacillus subtilis FZB37. J. Plant Dis. Prot. 111:583-597.

Idriss, E. E. S., Makarewicz, O., Farouk, A., Rosner, K., Greiner, R., Bochow, H., Richter, T., and Borriss, R. 2002. Extracellular phytase activity of Bacillus amyloliquefaciens FZB 45 contributes to its plantgrowth-promoting effect. Microbiology 148:2097-2109.

Kamilova, F., Kravchenko, L. V., Shaposhnikov, A. I., Azarova, T., Makarova, N., and Lugtenberg, B. 2006. Organic acids, sugars, and Ltryptophane in exudates of vegetables growing on stonewool and their effects on activities of rhizosphere bacteria. Mol. Plant-Microbe Interact.19:250-256.

Kilian, M., Steiner, U., Krebs, B., Junge, H., Schmiedeknecht, G., and Hain, R. 2000. FZB24 Bacillus subtilis - mode of action of a microbial agent enhancing plant vitality. Pflanzenschutz-Nachr. Bayer (Ger. Ed.) 1:72-93.

Kloepper, J. W., Ryu, C.-M., and Zhang, S. 2004. Induced systemic resistance and promotion of plant growth by Bacillus spp. Phytopathology 94:1259-1266.

Kobayashi, M., Suzuki, T., Fujita, T., Masuda, M., and Shimizu, S. 1995. Occurrence of enzymes involved in biosynthesis of indole-3-acetic acid from indole-3-acetonitrile in plant associated bacteria, Agrobacterium and Rhizobium. Proc. Natl. Acad. Sci. U.S.A. 92:714-718.

Koga, J., Adachi, T., and Hidaka, H. 1991. Molecular cloning of the gene for indolepyruvate decarboxylase from Enterobacter cloacae. Mol. Gen. Genet. 226:10-16.

Koumoutsi, A., Chen, X.-H., Henne, A., Liesegang, H., Hitzeroth, G., Franke, P., Vater, J., and Borriss, R. 2004. Structural and functional characterization of gene clusters directing nonribosomal synthesis of bioactive cyclic lipopeptides in Bacillus amyloliquefaciens strain FZB42. J. Bacteriol. 186:1084-1096.

Kunst, F., and Rapoport, G. 1995. Salt stress is an environmental signal affecting degradative enzyme synthesis in Bacillus subtilis. J. Bacteriol. 177:2403-2407.

Kunst, F., Ogasawara, N., Moszer, I., Albertini, A. M., Alloni, G., Azevedo, V., Bertero, M. G., Bessières, P., Bolotin, A., Borchert, S., Borriss, R., Boursier, L., Brans, A., Braun, M., Brignell, S. C., Bron, S., Brouillet, S., Bruschi, C. V., Caldwell, B., Capuano, V., Carter, N. M., et al. 1997. The complete genome sequence of the gram-positive bacterium Bacillus subtilis. Nature 390:249-256.

Lambrecht, M., Okon, Y., Vande Broek, A., and Vanderleyden, J. 2000. Indole-3-acetic acid: A reciprocal signaling molecule in bacteria-plant interactions. Trends Microbiol. 8:298-300.

Landy, M., Warren, G. H., Roseman, S. B., and Colio, L. G. 1948. Bacillomycin, an antibiotic from Bacillus subtilis active against pathogenic fungi. Proc. Soc. Exp. Biol. Med. 67:539-541.

Lebuhn, M., Heulin, T., and Hartmann, A. 1997. Production of auxin and other indolic and phenolic compounds by Paenibacillus polymyxa strains isolated from different proximity to plant roots. FEMS (Fed. Eur. Microbiol. Soc.) Microbiol. Ecol. 22:325-334.

Loper, J. E., and Schroth, M. N. 1986. Influence of bacterial sources of indole-3-acetic acid biosynthetic on root elongation of sugar beet. Phytopathology 76:386-389.

Magie, A. R., Wilson, E. E., and Kosuge T. 1963. Indoleacetamide as an intermediate in the synthesis of indoleacetic acid in Pseudomonas savastanoi. Science 141:1281-1282.

Makarewicz, O., Dubrac, S., Msadek, T., and Borriss, R. 2006. Dual role of the PhoP P response regulator: Bacillus amyloliquefaciens FZB45 phytase gene transcription is directed by positive and negative interaction with the phyC promoter. J. Bacteriol. 188:6953-6965.

Mehouachi J, Iglesias, D. J., Tadeo, F. R., Agusti, M., Primo-Millo, E., and Talon, M. 2000. The role of leaves in citrus fruitlet abscission: Effects on endogenous gibberellin levels and carbohydrate content. J. Hortic. Sci. Biotechnol. 75:79-85.

Normanly, J., and Bartel, B, 1999. Redundancy as way of life-IAA metabolism. Curr. Opin. Plant Biol. 2:207-213.

Patten, C. L., and Glick, B. R. 1996. Bacterial biosynthesis of indole-3acetic acid. Can. J. Microbiol. 42:207-220.

Patten, C. L., and Glick, B. R. 2002. Role of Pseudomonas putida indoleacetic acid in development of the host plant root system. Appl. Environ. Microbiol. 68:3795-3801.

Pirson, A., and Seidel, F. 1950. Zell- und stoffwechselphysiologische Untersuchungen an der Wurzel von Lemna minor L. unter besonderer Berücksichtigung von Kalium- und Kalziummangel. Planta 38:431-473.

Robinette, D., and Matthysse. 1990. Inhibition by Agrobacterium tumefaciens and Pseudomonas savastanoi of development of the hypersensitive response elicited by Pseudomonas syringae pv. phaseolicola. J. Bacteriol. 172:5742-5749.

Ryu, C.-M., Farag, M. A., Hu, C.-H., Reddy, M., Wei H.-X., Paré P. W., and Kloepper, J. 2003. Bacterial volatiles promote growth in Arabidop- 
sis. Proc. Natl. Acad. Sci. U.S.A. 100:4927-4932.

Schmiedeknecht, G., Bochow, H., and Junge, H. 1998. Use of Bacillus subtilis as biocontrol agent. II. Biological control of potato diseases. J. Plant Dis. Prot. 105:376-386.

Steenhoudt, O., and Vanderleyden, J. 2000. Azosprillum, a free living nitrogen-fixing bacterium closely associated with grasses: Genetic, biochemical and ecological aspects. FEMS (Fed. Eur. Microbiol. Soc.) Microbiol. Rev. 24:487-506.

Talon, M., and Zeevaart, J. A. D. 1992. Stem elongation and changes in the levels of gibberellins in shoots tips induced by photoperiodic treatments in the long day plant Silene armeria. Planta 188:457-461.

Talon, M., Hedden, P., and Primo-Millo, E. 1990. Gibberellins in Citrus sinensis: A comparison between seeded and seedless varieties. J. Plant Growth Regul. 9: 201-206

Timmusk, S., and Wagner, E. G. H. 1999. The plant-growth-promoting rhizobacterium Paenibacillus polymyxa induces changes in Arabidopsis thaliana gene expression: A possible connection between biotic and abiotic stress responses. Mol. Plant-Microbe Interact. 12:951-959.
Vandeputte, O., Öden, S., Mol, A., Vereecke, D., Goethals, K., El Jaziri, M., and Prinsen, E. 2005. Biosynthesis of auxin by the gram-positive phytopathogen Rhodococcus fascians is controlled by compounds specific to infect plant tissues. Appl. Environ. Microbiol. 71:1169-1177.

Yamada, T. 1993. Role of auxin in plant-disease development. Annu. Rev. Phytopathol. 31:253-273.

Yao, A. V., Bochow, H., Karimov, S., Boturov, U., Sanginboy, S., and Sharipov, K. 2006. Effect of FZB24 Bacillus subtilis as a biofertilizer on cotton yields in field tests. Arch. Phytopathol. Plant Prot. 39:1-6.

Zimmer, W., Aparicio, C., and Elmerich, C. 1991. Relationship between tryptophane biosynthesis and indole-3-acetic acid production in Azospirillum: Identification and sequencing of a $\operatorname{trp} G D C$ cluster. Mol. Gen. Genet. 229:41-51.

\section{AUTHOR-RECOMMENDED INTERNET RESOURCE}

Lemnatec GmbH website: www.lemnatec.de 